\title{
Water Demand Management in Jordan
}

\author{
Nadhir Al-Ansari ${ }^{1 *}$, N. Alibrahiem², M. Alsaman ${ }^{2}$, Sven Knutsson ${ }^{1}$ \\ ${ }^{1}$ Lulea University, Lulea, Sweden \\ ${ }^{2} \mathrm{Al}$ al-Bayt University, Mafraq, Jordan \\ Email: “Nadhir.alansari@ltu.se, n.alibrahiem@gmail.com, alsaman_marwan@yahoo.com, Sven.Knutsson@ltu.se
}

Received November 18, 2013; revised December 18, 2013; accepted December 25, 2013

Copyright (C) 2014 Nadhir Al-Ansari et al. This is an open access article distributed under the Creative Commons Attribution License, which permits unrestricted use, distribution, and reproduction in any medium, provided the original work is properly cited. In accordance of the Creative Commons Attribution License all Copyrights (C) 2014 are reserved for SCIRP and the owner of the intellectual property Nadhir Al-Ansari et al. All Copyright (C 2014 are guarded by law and by SCIRP as a guardian.

\section{ABSTRACT}

Jordan is located in the Middle East in the eastern Mediterranean. It has a surface area of approximately 90,000 $\mathbf{k m}^{2}$ and its population reaches 6.3 million. Jordan is the fourth driest countries in the World and water demand exceeds Jordan's available water resources. Annual per capita water availability has declined from $3600 \mathrm{~m}^{3} / \mathrm{year}$ in 1946 to $145 \mathrm{~m}^{3} /$ year today. It is estimated that the population will continue to grow from about 5.87 million in 2008 to over 7.80 million by 2022 . Total projected water demand will be 1673 million cubic meters by 2022 . Fifteen-year complete records for water consumption were studied to see the supply and demand variation with time. It had been noticed that water demand management will address the actual needs for water. This management program will ensure further reduction in water use, reduce water loses through the distribution supply net, prevent pollution. In addition, it will help minimize water disposal in nature, make efficient use of available water resources, plan for future new water resources prudently and finally impose a real cost for water supply that would be acceptable. In addition to the above, public awareness program is to be put in action. Such a program should be used in schools as well as the media. The public is to be aware of the problem and how they can assist with overcoming the water shortage crisis.

\section{KEYWORDS}

Water Management; Water Demand Management; Water Scarcity; Jordan

\section{Introduction}

Jordan is located in the eastern Mediterranean and it has a surface area of approximately $90,000 \mathrm{~km}^{2}$ (Figure 1). Jordan's population is around 6.3 million and it is estimated that the population will be 7.8 million in 2022 [1]. The most distinctive topographic features of Jordan are the Rift Valley, a narrow strip of highlands (with a maximum elevation of $1600 \mathrm{~m}$ above sea level), the steppe, the desert zone and the Dead Sea (426 m below sea level in 2010).

Mediterranean climate prevails west of Jordan which is characterized by dry hot summers, mild wet winters and extreme variability in rainfall during the year as well as from year to year. The climate in the highlands is characterized by cold winter and mild summer. Jordan Rift Valley and Aqaba have a subtropical climate-hot in summer and warm in winter. The steppe desert has a

\footnotetext{
${ }^{*}$ Corresponding author.
}

continental climate with large variations in temperature. Precipitation is very low and it ranges from 30 to 600 $\mathrm{mm}$ annually. About $93.5 \%$ of the country has less than $200 \mathrm{~mm}$ of rainfall, and only $0.7 \%$ of the country has annual precipitation of more than $500 \mathrm{~mm}$ [2]. The rainy season starts in November and ends in April. Most of the country (83\%) is composed of desert and desert steppe.

Jordan is considered as one of the poorest countries in its water resources. About $93 \%$ of the total precipitation which amounts to 8.2 billion $\mathrm{m}^{3}$ is lost by evaporation. The country is estimated below the poverty line by 682 million $\mathrm{m}^{3} /$ year and developed surface water potential was approximately 295 million $\mathrm{m}^{3}(\mathrm{MCM})$ in 2007, which is projected to reach 365 MCM by 2022 [2]. Surface water resources form about $37 \%$ of the total water supply from 16 basins (Figure 2). Yarmouk accounts for almost $50 \%$ of the country's surface water resources.

Ground water accounts for about 54\% of water supply in Jordan from 12 groundwater basins (Figure 3). Re- 


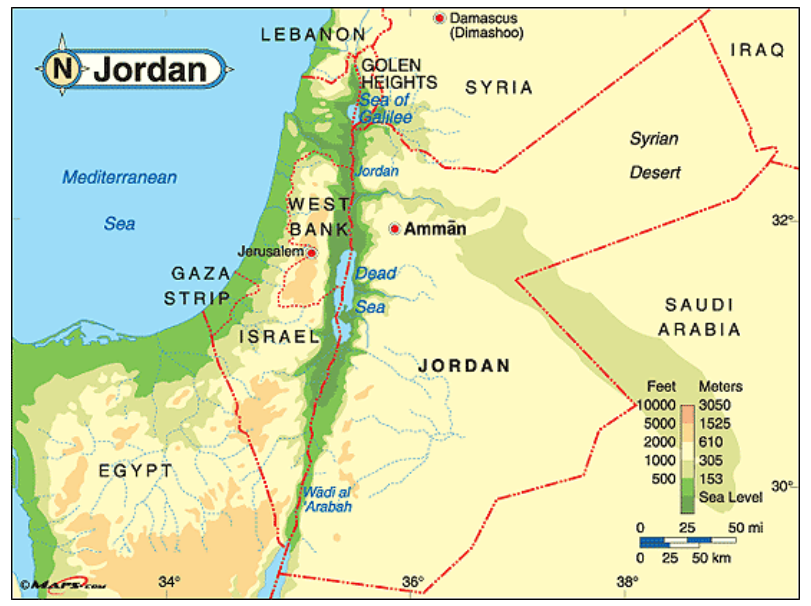

Figure 1. Map of Jordan.
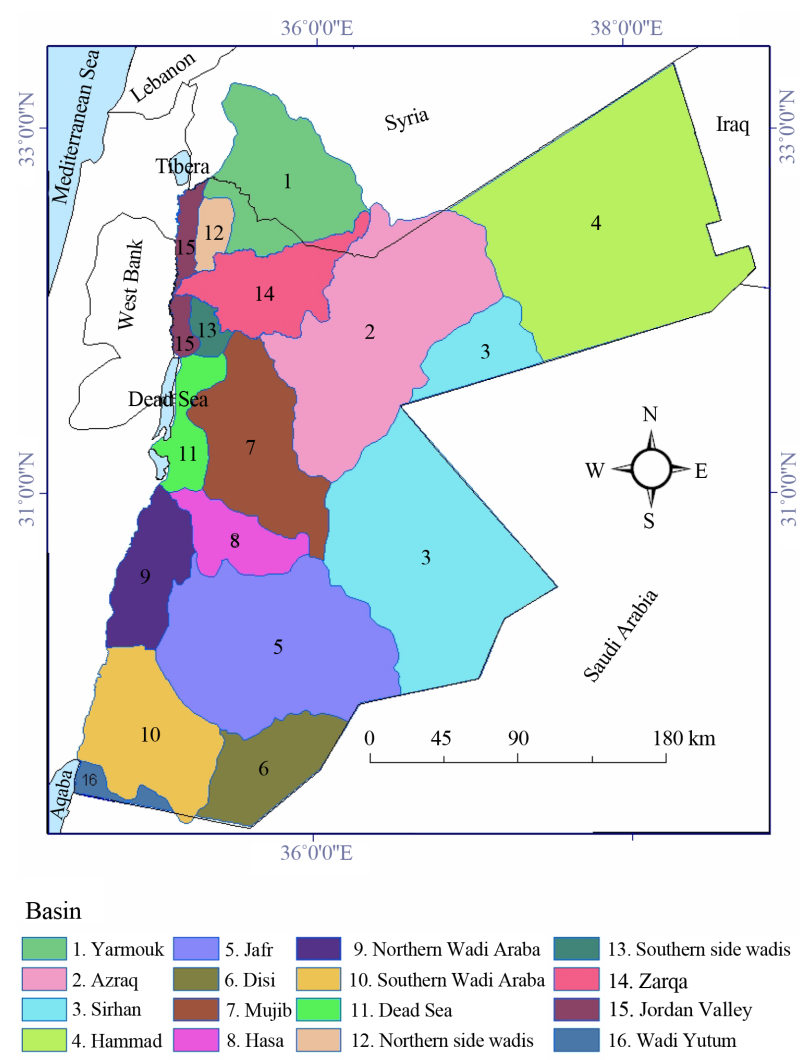

Figure 2. Surface water basins of Jordan.

newable ground water resources are 450 MCM per year with a safe yield of 275.5 MCM per year [3]. Abstraction of ground water is beyond sustainable limits causing a deficit of 151 MCM per year in 2007 as an example [2].

Other sources for water are fossil water, treated wastewater (110 MCM in 2009) and brackish water.

This research highlights the importance of adopting the water demand strategy which will decrease the gap between water supply and demand and conserve the water resources of Jordan.

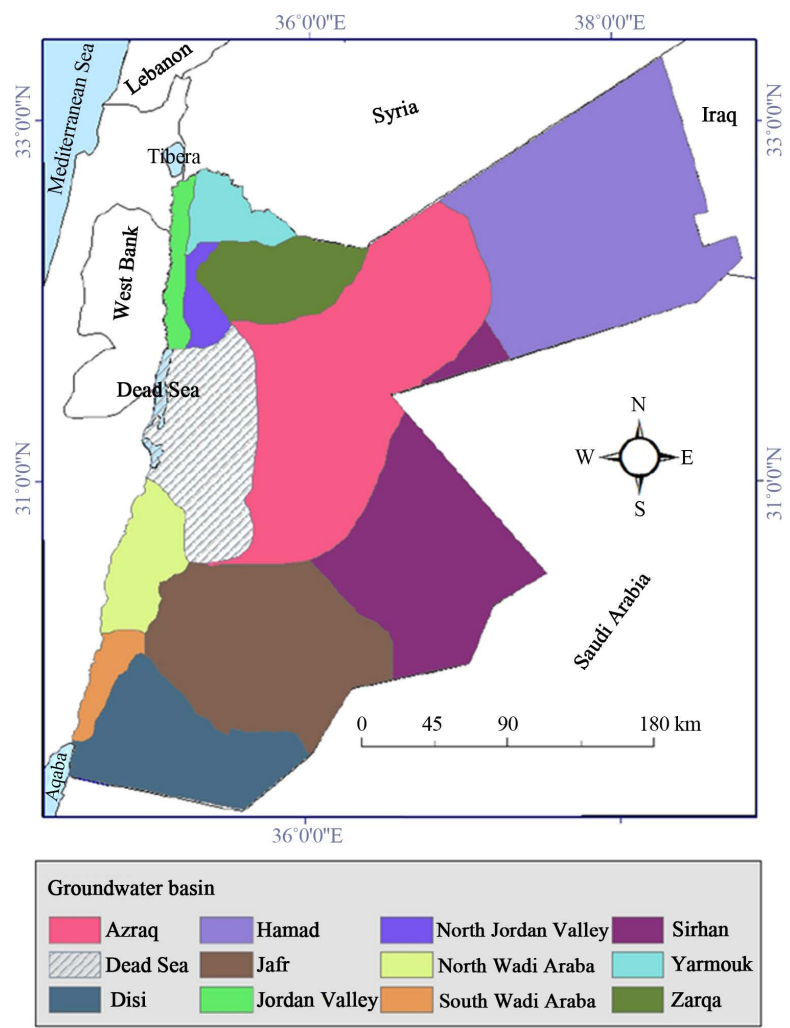

Figure 3. Ground water basins in Jordan.

\section{Water Consumption}

In Jordan water is supplied from three main sources. The first is ground water (about 54\%), while Surface water contributes about $37 \%$ and the remainder is from treated wastewater. It should be mentioned however, that the contribution of treated wastewater is increasing with time where it was 7 MCM in 1984 and it increased to about 67 MCM in 1996. According to Aquastat [4] water withdrawal by source in 2005 was, Groundwater, surface water and wastewater contributions were 59\%, 31\% and 9\%. Bar et al. [5] showed that renewable water resources are sharply declining in Jordan and allocation per capita per day is about $140 \mathrm{l}$ for domestic use. This is due to the sharp increase in population where the per-capita water availability, which dropped from $3600 \mathrm{~m}^{3}$ in 1946 to 145 $\mathrm{m}^{3}$ in 2008 [2]. UNESCO [2] stated that by 2022, the population may exceed 7.8 million, and total water demand may reach1 1673 MCM. Water deficit of 659 MCM (2009) could be reduced to 457 MCM by 2022. Twenty eight dams with a total storage capacity of 368 MCM were constructed between 1950 and 2008 and at the same time, locations were identified for a number of reservoirs that would give the potential to add 444 MCM to Jordan's water storage capacity.

The data indicates that municipal water consumption increased by an average of $8 \%$ per year while it was 6.6 and $3 \%$ within the industrial and agricultural sectors re- 
spectively. The increase of water consumption in these sectors is due to the increase in investments in these sectors. According to the studied records the average consumption per capita in the municipal sector reaches 138 l/day while it reached 147 and 145 l/day/capita in 2010 and 2011 respectively [6]. This amount decreases to 70 75 l/day when water losses are taken into consideration. Within the industrial and agricultural sector the allocated water per capita (as an average) reaches about 126 and 493 l/day/capita for the industrial and agricultural sectors respectively. These figures indicate that the total share per capita reaches 129 l/day/capita in 1998 (see Table 1). Comparing this figure with neighboring countries show that the allocation per capita per day where it reaches 1112, 5285 and 467 in Egypt, Iraq and Israel respectively [7] and it reaches 2162 and 1752 in the United States and Canada respectively [8] and 2251 per day per capita in UK [9]. This indicates that the allocation per capita in Jordan is about $11 \%$ than it is in the United States. The allocation per capita in Jordan in 1993 was about 386 cubic meter per year [10]. In 2005 however; it was 165 cubic meter per year [4]. Expected allocations in 2015, 2025 and 2050 are 130, 121, 100 cubic meter per capita per year respectively [11]. El-Fadel and Maroun [12] stated that Jordan water scarcity is $53.4 \%$.

Municipal water consumption is related to the average income per capita and water consumption increases with the increase of income $[7,8]$. Jordan is considered as a medium level country when in the income per capita in considered. Despite this fact the municipal water consumption reaches $21 \%$ of the total water consumption. This figure is high when compared to high income per capita countries where it is $15 \%$ and it is less than that in developing countries where it reaches 7\% (Table 2) [13]. In high income per capita countries, industrial water consumption is usually high where it reaches $46 \%$ of the total consumption indicating high development in the industry. In development countries industrial water consumption is about $7 \%$ of the total water consumption. In Jordan this percentage reaches $4.1 \%$ (Table 2). As far as the agricultural sector is concerned, the water consumption reaches $39 \%$ and $86 \%$ in developed and developing countries respectively (Table 2). In Jordan it reaches $74.9 \%$ only. It is noteworthy to mention that the low water consumption in developed countries reflects the modern technology used in irrigation.

According to the Ministry of Water and Irrigation [6], Municipal water supplied in 2010 reached 313.4, 330 and 330.1 MCM in 2009, 2010 and 2011 respectively. This gives 144,147 and 150 l/capita/day for these years respectively. Most of the supplied water is consumed in the capital Amman (Table 3). Furthermore, the total amount of water released for drinking and irrigation purposes in 2010 and 2011 were 229.675 and 222.272 MCM [6].

Table 1. Water consumption for the period 1984-1998.

\begin{tabular}{|c|c|c|c|c|c|}
\hline \multirow{2}{*}{ Year } & \multirow{2}{*}{ Population (million) } & \multicolumn{4}{|c|}{ Water Consumption (l/day/capita) } \\
\hline & & Municipal & Industrial & Agricultural & Total \\
\hline 1985 & 2.700 & 94 & 22 & 508 & 624 \\
\hline 1986 & 2.798 & 132 & 24 & 452 & 608 \\
\hline 1987 & 2.896 & 141 & 23 & 539 & 703 \\
\hline 1988 & 3.001 & 150 & 36 & 561 & 747 \\
\hline 1989 & 3.111 & 149 & 32 & 550 & 731 \\
\hline 1990 & 3.468 & 141 & 34 & 520 & 695 \\
\hline 1991 & 3.701 & 132 & 31 & 453 & 616 \\
\hline 1992 & 3.844 & 148 & 25 & 499 & 672 \\
\hline 1993 & 3.998 & 150 & 23 & 498 & 671 \\
\hline 1994 & 4.139 & 145 & 26 & 481 & 652 \\
\hline 1995 & 4.152 & 162 & 26 & 462 & 650 \\
\hline 1996 & 4.291 & 155 & 26 & 440 & 621 \\
\hline 1997 & 4.441 & 147 & 27 & 412 & 586 \\
\hline 1998 & 4.601 & 143 & 26 & 427 & 596 \\
\hline Average & & 138 & 21 & 493 & 657 \\
\hline
\end{tabular}


Table 2. Percentage of water use according to the type of use (source of data for developed and developing countries is [11]).

\begin{tabular}{cccc}
\hline Type of water use & Developed Countries \% & Developing countries \% & Jordan \% \\
\hline Municipal & 15 & 7 & 21 \\
Industrial & 46 & 7 & 4.1 \\
Agricultural & 39 & 86 & 74.9 \\
\hline
\end{tabular}

Table 3. Amounts of water production and supply for 2011in million cubic meters (MCM).

\begin{tabular}{cccc}
\hline Governorate & Water Production 2011(MCM) & Water supply 2012(MCM) & Per capita (l/day) \\
\hline Capital (Amman) & 140.2 & 132.2 & 150 \\
Zarka & 49.2 & 50.1 & 147 \\
Irbid & 38.8 & 41 & 101 \\
Mafraq & 24.6 & 20.4 & 190 \\
Balqa & 12.3 & 26.1 & 171 \\
Karak & 19.7 & 15.4 & 173 \\
Tafileh & 3.5 & 3.5 & 109 \\
Maan & 13.3 & 10.5 & 243 \\
Jarash & 3.3 & 5.2 & 76 \\
Ajloun & 2.5 & 3.6 & 70 \\
Madaba & 11.6 & 6.7 & 118 \\
Aqaba & 22.1 & 15.3 & 308 \\
Total & 140.5 & 330.1 & 145 \\
\hline
\end{tabular}

The highest percentage of water consumption is in the field of Agriculture followed by municipal and then industrial sector (Figure 4). Nimah [11] indicated that in 2050 the available water in Jordan will be 100 cubic meters/capita/year.

\section{Water Demand}

An attempt had been made to calculate the water requirements in Jordan till 2025. Three scenarios were used. The first was carried out assuming that water consumption is at constant rates up to 2025.

The rates of consumption considered were 50.4, 9.5 and 180 cubic meters for municipal, industrial and agricultural sectors respectively. Population growth rate was assumed to be $3.6 \%$ for the period $1997-2000$ and it was assumed to decrease by $0.1 \%$ every 5 years. The results showed that the population will reach 10.774 million in 2025. Accordingly, water demand will be 2584 MCM and that means the water deficit will reach 1187 MCM in 2025 (Table 4).

In the second scenario, the population growth rate was taken as in the first scenario and the water allocation was considered 200l/day/capita according to WHO recommendations. The industrial water consumption was con- sidered to match medium income per capita. In this scenario, municipal water consumption increased to reach 786.5 MCM and the industrial water consumption to be 172.4 MCM in 2015. The water requirements of the agricultural sector were considered to be the remainder of the available water. This was assumed on the condition that up to date water irrigation techniques are used in such a way to improve the productivity of the land (Table 4).

Water consumption for the period 1984 to 1997 was used in the third scenario. In addition the expected water resources defined by the Ministry of Water and Irrigation [14] were used in this scenario. The results showed that municipal water consumption reached 597.4 MCM in 2025 which indicates that there was $4.1 \%$ increase annually. The allocation per capita per day in 2025 is 152 1/day/capita. As far as the industrial and agricultural sectors are concerned, the consumption increase to 170.5 and $1228 \mathrm{MCM}$ in 2025 indicating an increase of 5.8 and 2.2\% annually respectively (Table 4).

The Ministry of Water and Irrigation [6] published the projected water demand for the year 2025 (Figure 5). In this report the municipal, industrial and agricultural demands were 613,117 , and $700 \mathrm{MCM}$ respectively. It was 
Table 4. Expected future water demand for the years 2020 and 2025 using three scenarios.

\begin{tabular}{|c|c|c|c|c|c|c|c|}
\hline \multirow{2}{*}{ Year } & \multirow{2}{*}{$\begin{array}{l}\text { Expected water } \\
\text { resources(MCM) }\end{array}$} & \multirow{2}{*}{$\begin{array}{l}\text { Expected } \\
\text { population } \\
\text { (million) }\end{array}$} & \multicolumn{4}{|c|}{ Expected water Requirements (MCM) } & \multirow{2}{*}{ Balance } \\
\hline & & & Municipal & Industrial & Agricultural & Total & \\
\hline \multicolumn{8}{|c|}{ First Scenario } \\
\hline 2020 & 1392 & 9.294 & 468.4 & 88.3 & 1672.9 & 2229.6 & -837.6 \\
\hline 2025 & 1398 & 10.774 & 543.0 & 102.4 & 1939.3 & 2584.7 & -1186.7 \\
\hline \multicolumn{8}{|c|}{ Second Scenario } \\
\hline 2020 & 1392 & 9.294 & 678.5 & 139.4 & 574.1 & 1392 & 0.0 \\
\hline 2025 & 1398 & 10.774 & 786.5 & 172.4 & 439.1 & 1398 & \\
\hline \multicolumn{8}{|c|}{ Third Scenario } \\
\hline 2020 & 1250 & 9.294 & 549.1 & 154.2 & 1158.2 & 1861.6 & -611.6 \\
\hline 2025 & 1275 & 10.774 & 597.4 & 170.5 & 1228.1 & 1996.0 & -721.0 \\
\hline
\end{tabular}

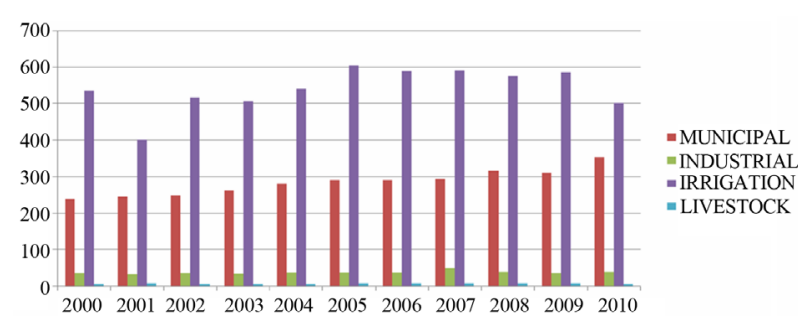

Figure 4. Type of water use in Jordan in million cubic meters (MCM) [5].

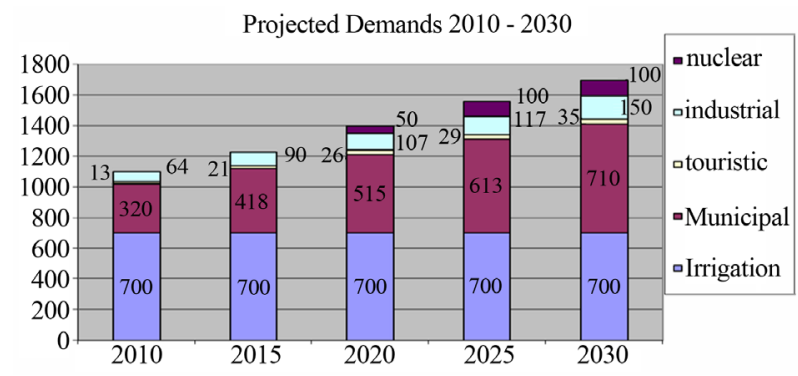

Figure 5. Projected water demand in Jordan [6].

also noticed that they added 100 and 29 MCM as nuclear and touristic water demands. In addition, the same report showed that the total demand will reach 1695 MCM in 2030 (710, 150, 700, 100, 35 MCM for municipal, industrial, agricultural, nuclear and touristic water demands respectively). Jordan's Strategy Plan [1] indicated that the available water in 2022 is 1632 MCM (Figure 6).

\section{Water Demand Management}

Continuous increase of water demand in Jordan is causing a severe problem due to the scarcity of water resources. To close the gap between supply and demand, the government used to invest in projects that can provide a new source for water. These projects include sur- face water, groundwater (renewable or nonrenewable) even if it was consuming the un- renewable groundwater resources. It had been noticed that about $121 \%$ of the safe yield were exhausted which caused depletion of water table and increase of salinity of ground water. Water demand increased 250\% in 1997 than it was in 1970 and this value in fact exceeded the population growth rate [14]. This rapid increase in demand is mainly due to the expansion of irrigation projects that does not use up to date techniques. Irrigated areas were 336 thousand acres in 1976 and became 770 thousand acres (Ministry of Water and irrigation, 2002). Flood irrigation consumes 1164 - 1205 cubic meter/year on the average. All this intensified the problem and applied what is referred to as water stress and Jordan is considered in level 4 in the water stress. This implies that Jordan is consuming more than $40 \%$ of the available renewable water i.e. it is consuming $160 \%$ of its renewable water resources [15].

Jordan's ability to cope with the scarcity of water resources depends on several factors such as the financial and economic ability of the country. According to the World Bank criteria, Jordan is within the category of countries with low average income, where per capita Jordanian GNP is approximately U.S. \$ 1698.6 [16]. In such a case, Jordan is of low average income and high water stress country. This implies that Jordanian ability to invest in the water sector is very low (6\%) to be paid equally by the state and individuals. In developed countries, the contribution of the state does not exceed $1 \%$ of GNP [15]. In this case Jordan must depend on outer resources for the development of its project in the water sector [7] due to poor economic resources. In addition, the agricultural sector consume e high water with the absence of any regulations or legislations that controls the use and preventing pollution of the water resources $[2,17,18]$. 


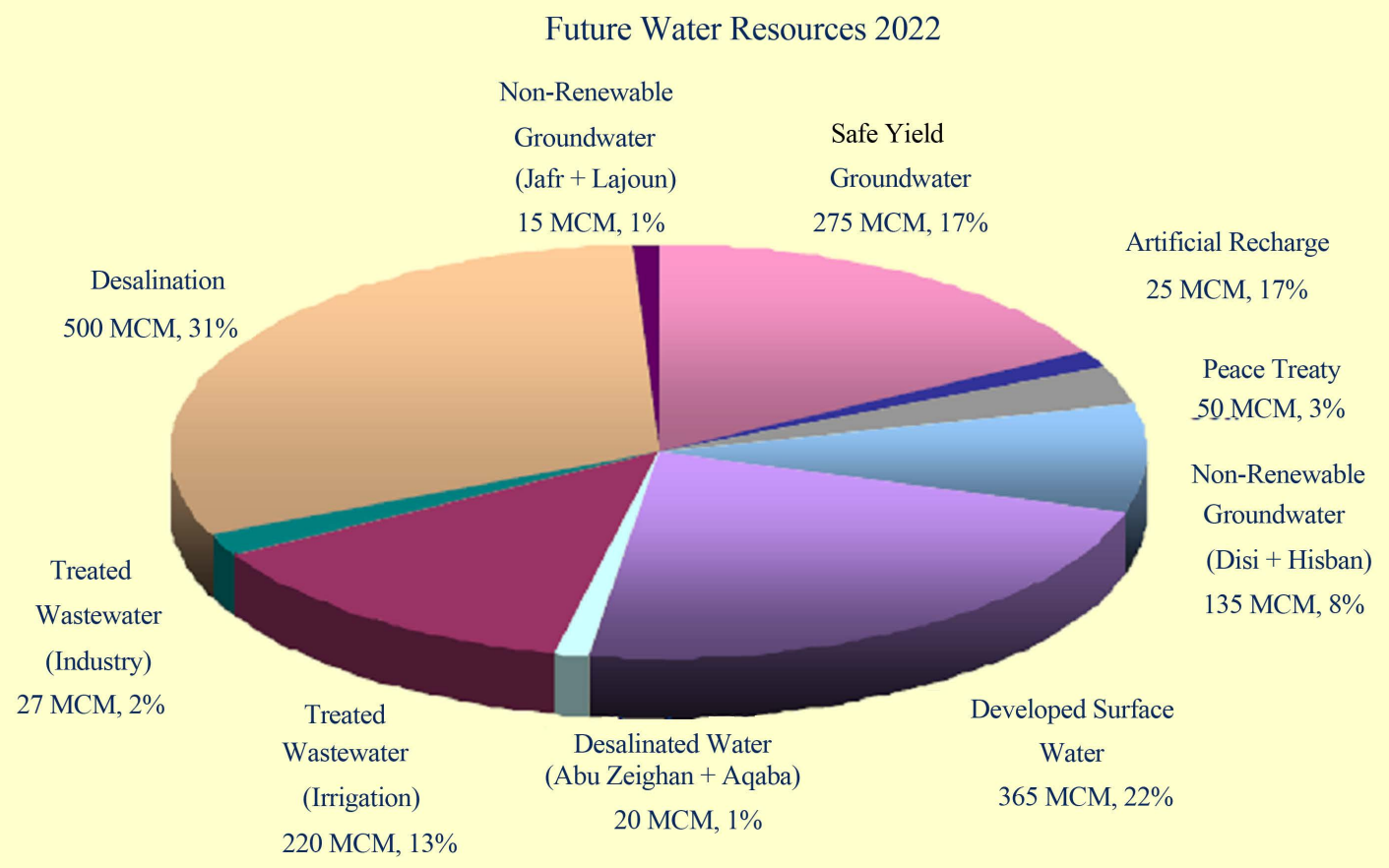

Figure 6. Future available water resources in Jordan 2022 [1].

The water sector in Jordan is in desperate need to fulfill the goals of the national water policy through the use of modern techniques in development of water resources and water demand management [19] due to the lack of required water and financial support to change the type of agricultural water consumption. This can be achieved through sparing some of the water used for agricultural purposes to be used for municipal and industrial development. This would create job opportunities and raise the income which can help to import food from other countries when required. This is attributed to the high productivity per cubic meter of water in the industrial sector than in the agricultural sector, because of the climatic conditions and the inability to use the modern techniques of irrigated agriculture as well as the low prices of irrigation water compared to industrial and domestic consumption.

\section{Discussion}

There are number of factors which led to excess water use. Among these factors are:

1. Encouraging agricultural expansion: Jordanian government pursues a policy of expansion in the area of irrigated land to invest in the agricultural sector. There are policies adopted by the government in supporting farmers, where many government and private institutions were established to support finan- cially and technically the farmers. Among these policies is the distribution of agricultural land policy, especially in the Jordan Valley area. These policies are practiced in the absence of comprehensive planning for Agricultural Development and conservation of the water resources

2. The concept of the relationship between the ownership of the land and water ownership: All the laws and legislation of Jordan concerning water indicate that all sources of water located above or underground property of the state. Jordanian legislation grants licenses drilling wells for the private sector and on their own expense. This has a major role in draining water resources.

The policy of granting water without charge or at nominal prices: The policy of Jordan to support the agricultural sector in granting water to farmers free of charge or very low tariff do not conforms at all to the true cost of water. This encourages farmers using water available and allocated to them without regard to the actual requirement of agricultural crops.

Water use control: Despite the existence of powerful water resources development and management in Jordan, but that the role of water use control is still tainted by a lot of shortcomings. There should be social justice in the distribution of water to meet the actual requirements only and to oblige users at various levels practice the most appropriate means to rationalize consumption and the 
introduction of modern irrigation techniques.

Currently available water resources are not sufficient to meet demand, as the practice used is to develop new sources of the so-called Water supply management. What is needed now is a comprehensive management of water resources which requires changing the pattern of consumption in various fields and re-use for different purposes, and reduce the wastage of water for all uses, in order to use optimally and to maximize the benefit and achieve a balance between the expected benefits of the use of water and the cost of water supply to achieve the needs this is referred to water demand management. In this context the management ensures optimal use of water resources, in addition to improving its management and preserving the quality and quantity.

The main motivations for adopting this approach can be summarized as follows:

1. Scarcity of water resources.

2. The general trend for Jordan now is to resort the production of water from alternative sources of high costs, such as desalination of sea water rather than resorting to reduce wastage of water, controlling water consumption pattern and the adoption of a comprehensive water policies that take into account the available water conditions as well as the ongoing economic and social progress.

3. Lack of accurate information about water losses.

4. Lack of good environmental awareness program to preserve water resources, has led to a large proportion of water to be wasted.

5. Most of the existing water resources are shared with Arab countries and Israel.

6. The huge number of technical personnel, which led to confusion in the decision-making. There are 11.4 personnel for every 1000 water house pipe link [20] while the international standard is 3 - 4 for every 1000 water house pipe link [21].

Water demand management will address the actual needs for water not the demand for water. In this context it will ensure further reduction in water use, reduce water loses through the distribution supply net, prevent pollution and waste water disposal in nature, efficient use of available water resources, prudent future planning for new water resources and finally imposing real cost for water supply that would be acceptable. In addition to the above, public awareness program is to be put in action. Such a program should be used in schools as well as the media. The public are to be aware of the problem and how they can assist to overcome the water shortage crisis.

\section{Conclusions}

Jordan is considered as one of the poorest countries in its water resources. A sample of 15-year complete record for water consumption was investigated. The results showed that water deficit is increasing with time. To overcome the water deficit between supply and demand, it is believed that water demand management program should be adopted. Such a program will help reduce water use and water loss through the distribution supply net, prevent pollution and waste water disposal in nature, make efficient use of available water resources, plan for future new water resources prudently, and finally impose a real cost for water supply that would be acceptable. Water demand management program will redefine water allocation priorities (such as reducing agricultural water use), and help develop new technologies for use of non-conventional water resources (example waste-water recycling). To protect public health and the environment, water quality degradation should be reversed.

In addition to the above, public awareness program is to be put in action. It is noteworthy to mention that public awareness program is to be adopted which will make people aware of the seriousness of the problem so that they can contribute to solving it by changing the water consumption pattern.

\section{Acknowledgment}

Most of the work presented in this paper forms part of the second Author's Master Dissertation submitted to $\mathrm{Al}$ al-Bayt University in Jordan. Thanks to Dr. Ali El-Naqa of The Hashemite University, Jordan for his assistance. The research presented has been financially supported by Luleå University of Technology, Sweden and by "Swedish Hydropower Centre-SVC" established by the Swedish Energy Agency, Elforsk and Svenska Kraftnät together with Luleå University of Technology, The Royal Institute of Technology, Chalmers University of Technology and Uppsala University. Their support is highly appreciated.

\section{REFERENCES}

[1] Water for Life, Jordan’s Water Strategy 2008-2022, 2008. http://web.idrc.ca/uploads/user-S/12431464431JO_Water -Strategy09.pdf

[2] UNESCO, "Managing Water under Uncertainty and Risk," The United Nations World Water Development Report 4, 2012.

[3] FAO (Food and Agriculture Organization of the United Nations), "Irrigation in the Middle East Region in Figures: AQUASTAT Survey 2008,” FAO, Rome, 2008. www.fao.org/nr/water/aquastat/countries_regions/jordan/j ordan_cp.pdf

[4] Aquastat, FAO, Countries, Regions, Transboundary River Basins, Jordan, 2013.

http://www.fao.org/nr/water/aquastat/countries_regions/J OR/index.stm

[5] J. Barr, S. Grego, E. Hassan, M. Niasse, W. Rast and J. 
Talafré, "Regional Challenges, Global Impacts, in Managing Water under Uncertainty and Risk,” UN World Water Development Report 4, Chapter 7, 2012.

[6] Ministry of Water and Irrigation, Annual Report, 2011.

[7] World Bank, "A Strategy for Managing Water in the Middle East and North Africa, "Washington DC, 1995, Table A-4, 1995, p. 68.

[8] The Economist, "Pocket World in Figures," 3rd Edition, the Economist Books Ltd., London, 1993, p. 82.

[9] R. Alkhaddar, W. Sheely and N. Al-Ansarri, "Jordan's Water Resources, Supply and Future Demand,” Water International, Vol. 30, No. 3, 2005, pp. 294-303. http://dx.doi.org/10.1080/02508060508691870

[10] R. Roger and P. Lydon, Ed., "Water in the Arab Word: Perspectives and Prognoses,” Harvard University, 1993.

[11] M. Nimah, "Water Resources,” In: M. K. Tolba and N. W. Saab, Eds., Arab Environment and Future Challenges, Chapter 5, The Arab Forum For Environment and Development, 2008.

[12] M. El-Fadel, and R. Maroun, "Virtual Water Trade as an Adaptation Demand Management of Climate Change Impact on Water Resources in the Middle East,” In: F. Zereini and H. Hotzl, Eds., Climatic Changes and Water Resources in the Middle East and North Africa, Springer, 2008, 552 p. http://dx.doi.org/10.1007/978-3-540-85047-2_9

[13] UN, "World Economic and Social Survey: Some Dimen- sions of Economic and Social Change, Should We Worry About Water,” 1996, pp. 259-276.

[14] Ministry of Water and Irrigation, Economic and Social Development Plan 1998-2002, Water Sector, 2002.

[15] M. Hadadeen, "Environmental Letter, World Water Day, Jordan,” 1998, pp. 6-8.

[16] Jordanian Central Bank, Monthly Statistical Report, Vol. 25, No. 3, 1999.

[17] WMO-World Meteorological Organization, General Evaluation of Fresh Water Resources in the World, Stockholm, 1992.

[18] J. Bartram and R. Balance, Eds., "Water Quality Monitoring-A Practical Guide to the Design and Implementation of Freshwater Quality Studies and Monitoring Programmes, United Nations Environment Programme and the World Health Organization,1966.

[19] O. Al-Jajyooci and M. Shatnawi, "Analysis of Future Water Policies in Jordan Decision Support Systems," Water Resource Development, Vol. 31, 1995, pp. 325327.

[20] Ministry of Water and Irrigation, Annual Report, 1988.

[21] I. Serageldin, "Water Supply, Sanitation and Environmental Sustainability, the Financing Challenge," Report No. 13728, 1994. 